\title{
EL CONTROL EXTERNO COMO \\ RETROALIMENTADOR DE LOS PROGRAMAS \\ SOCIALES. DISEÑO DE UNA METODOLOGÍA \\ PARA EL CONTROL EXTERNO DE LOS \\ PROGRAMAS SOCIALES IMPLEMENTADOS \\ EN LA PROVINCIA DE SANTA FE EN \\ EL ÚLTIMO QUINQUENIO (2006-2010) \\ PARA LOS NIÑOS DE CERO A DOCE AÑOS
}

\author{
Tesista \\ Diego Salzman \\ Director de tesis \\ José Carlos Farías
}

La falta de evaluación de los programas sociales en América Latina produce un grave problema para conocer el verdadero resultado de las políticas públicas implementadas y determinar cómo, en el caso que corresponda, deban reformularse. Esto impide verificar el real inconveniente que genera la pobreza para los países de América Latina. Esa carencia de examen de las políticas sociales obedece a las siguientes cuestiones: i) los gobiernos no tienen los incentivos convenientes para apropiarse del resultado de la evaluación; ii) problemas para captar la información, ya sea para el diseño, ejecución y seguimiento de las políticas públicas; iii) falta de personal calificado para la evaluación de las políticas públicas y iv) baja participación de la sociedad civil.

El objetivo de este trabajo fue verificar la importancia del control externo en el ciclo de la política pública dentro del funcionamiento del Estado y cómo esa función puede beneficiar a la ejecución de las políticas sociales.
El Estado cuando actúa en un contexto capitalista y generador de desigualdades, debe recurrir a intervenciones que posibiliten mejorar la calidad de vida de sus ciudadanos para revertir el patrón de inequidades que se van generando. Por eso, afirmo que no se pueden desligar las políticas económicas de las políticas sociales ya que están íntimamente relacionadas. Esta afirmación significa que cuando las políticas económicas generan desigualdades, la consecuencia posterior será la aparición de programas sociales que intenten revertirlas.

A partir del golpe militar de 1976 comenzó a implementarse un conjunto de medidas que tuvieron un grave impacto en la economía argentina. Con Martinez de Hoz se inicia un nuevo modelo económico basado en la acumulación agro-exportadora y financiera. Con esos cambios, se producía el fin del modelo de sustitución de importaciones. La desindustrialización iniciada en la dictadura militar 
y acentuada en los gobiernos menemistas provocó una grave caída en el empleo y, por ende, en la situación social argentina.

Cuando asume el Dr. Néstor Kirchner (2003-2007), se inicia un nuevo modelo macroeconómico, pasando del régimen de valorización financiera previo a un régimen de acumulación productiva con inclusión social. A partir de 2003, los gobiernos del Dr. Néstor Kirchner y de la Dra. Cristina Fernández inician una transformación de la economía del país, tratando de colocar al Estado en el centro de la escena, buscando la participación activa del Estado en la economía, en el sentido opuesto de lo que manifestaban sus antecesores que dejaban librado al mercado la política del país. Asimismo, se provoca un giro en la política social donde el aspecto central de de la extensión de la protección pública pasa a ser el empleo formal y las grandes instituciones universalistas, dejando de lado el anterior sistema cuyo rol primordial era la lucha contra la pobreza y las políticas focalizadas como garantía mínima de seguridad de los pobres.

Las causas que motivaron el desarrollo de esta investigación fueron principalmente tres: verificar cuáles son las causas que dieron origen a la aparición de políticas sociales en la Argentina, identificar y cuantificar el impacto que producen las políticas sociales en los ciudadanos y brindar a los ejecutores y controladores de políticas sociales una herramienta útil para la auditoría de las mismas.

El ámbito de investigación han sido las actividades de control externo de los programas sociales, y el problema se definió de la siguiente manera: ¿cuáles son las incongruencias normativas y operativas en los Programas Sociales implementados para niños de 0 a 12 años en la Provincia de Santa Fe en el último quinquenio (2006-2010)?

La investigación tuvo como objetivo general analizar las funciones de control externo de los programas sociales, para detectar la superposición de Programas, considerando relevantes los puntos de control y las incompatibilidades que se plantean entre los diferentes programas sociales para niños de cero a doce años en la Provincia de Santa Fe durante el último quinquenio (2006-2010), para mejorar la calidad de vida de los ciudadanos santafesinos.

Los objetivos específicos fueron: estudiar los conceptos claves relacionados con las Políticas Sociales, analizar las incongruencias normativas y operativas de los Programas Sociales, analizar la superposición entre diferentes Programas Sociales, evaluar las incompatibilidades de las Programas Sociales y examinar los puntos de control de requisitos de ingreso o de mantenimiento de los Programas Sociales.

Para la investigación, se utilizó el encuadre metodológico de tipo cualitativo. Se plantearon interpretaciones que incluyan conceptos teóricos, los que se fueron construyendo en ese mismo proceso de análisis con el fin de examinar el problema de estudio. Se realizó un análisis sistemático en el cual se evaluó cada caso. En la investigación se utilizó el método descriptivo ya que se buscó caracterizar el fenómeno analizando de manera más bien independiente de los conceptos o variables a los que se refieren.

El marco conceptual se desenvuelve en la lógica que impera en un Estado y que desencadena el modo de vida de sus habitantes. Por ello, los tres conceptos claves de Estado, Pobreza y Políticas Sociales como forma de intervención del Estado para reducir o eliminar la pobreza son las claves para empezar a delinear las relaciones que se producen dentro de un Estado.

Para desarrollar los diferentes tipos de Estado, me auxilié de una caracterización reciente realizada por Espina Prieto (2008). En cuanto a las funciones del Estado, utilicé el planteo de Musgrave y Musgrave (1992), haciendo hinca- 
pié en la función distributiva de la intervención del Estado. Para ello, se hace necesario arbitrar un conjunto de políticas sociales que promuevan el bienestar de la sociedad.

Las políticas sociales constituyen intervenciones del Estado sobre las relaciones que se reproducen en la Sociedad, produciendo un cambio que mejorará la vida de determinados sectores. Esta intervención surge cuando el Estado debe reparar la conflictividad social para poder sostener el engranaje del sistema capitalista. Y esta intervención se produce dentro del desarrollo del ciclo de las políticas públicas. Como parte del ciclo de las políticas públicas, introduje la función del control externo, como parte de la evaluación de ese ciclo. Esas políticas requieren ser evaluadas para mejorarlas, cambiarlas o eliminarlas, en su caso. En ese sentido, adquiere relevancia la evaluación de las políticas públicas. Dicha evaluación es el proceso que se analizan los objetivos establecidos comparándolos con los resultados logrados. Ello permitirá formular sugerencias para retroalimentar a la política pública.

En el caso de los órganos de control que nos compete a los fines de esta investigación, el trabajo de auditorías permite retroalimentar a las políticas públicas a través de las recomendaciones que surgen a las observaciones detectadas en la ejecución de los programas sociales. Es decir que, en el trabajo de auditorías desde los órganos de control se realiza una evaluación de la gestión de los programas sociales. La retroalimentación tiene como objetivo que el órgano auditado logre sus fines y objetivos propuestos y eso signifique una mejora para la ciudadanía, especialmente para los titulares de derecho a quienes se dirige la política pública implementada.

\section{ALGUNAS CONCLUSIONES}

En lo que refiere a las gestiones de gobierno de políticas sociales para niños de cero a doce años implementadas en la Provincia de Santa Fe en el período 2006-2010, podemos afirmar que entre el gobierno justicialista del Ing. Jorge A. Obeid (2003-2007) y el del gobierno socialista Dr. Hermes J. Binner (2007-2011) no se produjeron diferencias significativas. Ambos gobiernos implementaron un conjunto de medidas para la franja etaria analizada que venían impulsadas, en su mayoría, desde el Gobierno Central —Dr. Néstor Kirchner (2003-2007) y Dra. Cristina Fernández (2007-continúa) - y otras que fueron implementadas por el Gobierno del Dr. Obeid y mantenidas por el gobierno socialista del Dr. Binner.

La evaluación, y siempre hablando desde el control externo, debe convertirse en una instancia donde se destaquen los siguientes aspectos: 1) debe ser vista como una instancia normal y funcional a la política pública, ya no como una instancia de policía que sólo busca el error voluntario, el apartamiento de la normativa o el fraude; 2) debe detectar problemas en la confección de la normativa; 3) determinar o detectar los problemas de funcionamiento operativo del programa; 4) proponer una instancia de encuentro con el auditado que posibilite formular propuestas de corrección de los problemas detectados y 5) definir mecanismos de monitoreo o seguimiento de los problemas detectados con el objeto de verificar su solución en un plazo inmediato, o en su defecto, mediato.

No obstante, cabe mencionar algunas limitaciones en la ejecución de políticas sociales en la Provincia de Santa Fe: a) falta de generación de índices que permitan determinar cuantitativamente los efectos positivos o negativos de las políticas implementadas; b) se ha mantenido el criterio de beneficiario para referirse a aquellos que reciben las prestaciones, siendo que lo adecuado sería referirse a titulares de derechos; c) utilización de la medición de la pobreza analizando solamen- 
te el aspecto económico. Lo correcto sería la aplicación del enfoque multidimensional que tenga en cuenta todos los aspectos que hacen al respeto de los derechos humanos (derechos económicos, sociales, políticos y culturales); d) falta de contemplación de mecanismos de egreso en la normativa de los Programas y que no resulten un doble perjuicio: la disminución de los ingresos familiares y la falta de cumplimiento del objetivo del Programa; e) si bien existe normativa que garantiza el funcionamiento del organismo de control, así como obligatoriedad de los restantes organismos de la administración pública para proporcionar la información que aquellos soliciten, en la práctica no funciona esa colaboración en tiempo y forma; f) falta de realización de evaluaciones integrales de los programas sociales desde los órganos de control, que permitirían mejorar el diseño, desarrollo e implementación de los mismos; g) confeccionar los presupuestos provinciales contemplando unidades físicas y no solamente monetarias. Esto posibilitaría realizar las auditorías de gestión y conocer el insumo, producto y necesidades que trata de satisfacer la ejecución de la política pública, tanto en la etapa ex ante (programación) como ex post (concluida la ejecución) y h) falta de utilización de sistemas informáticos para controles para evitar dobles prestaciones e incompatibilidades.

Si bien, estas cuestiones han tenido un avance, tanto desde el punto de vista del control externo como de los órganos auditados, queda un largo camino por recorrer que deberá ser transitado con un cambio de mentalidad de los órganos de control que deben refundarse hacia esta nueva visión de involucramiento hacia los programas sociales y convertirse en un insumo para el órgano auditado y, así, serán vistos por la ciudadanía en general como estamentos válidos para la retroalimentación de la gestión y; con órganos auditados que inicien un proceso de reconocimiento del órgano de control como un complemento constructivo, en vez de regresivo si solo se limitara a verificar el grado de cumplimiento de la norma, integrándolo a la gestión de los programas sociales.

\section{PARA CITAR ESTE ARTÍCULO:}

Salzman, Diego (2014). "Recensión de tesis: "El control externo como retroalimentador de los programas sociales. Diseño de una metodología para el control externo de los programas sociales implementados en la provincia de Santa Fe en el último quinquenio (2006-2010) para los niños de cero a doce años"”, DAAPGE, año 14, №23, 2014, pp. 177-180. Santa Fe, Argentina: UNL. 